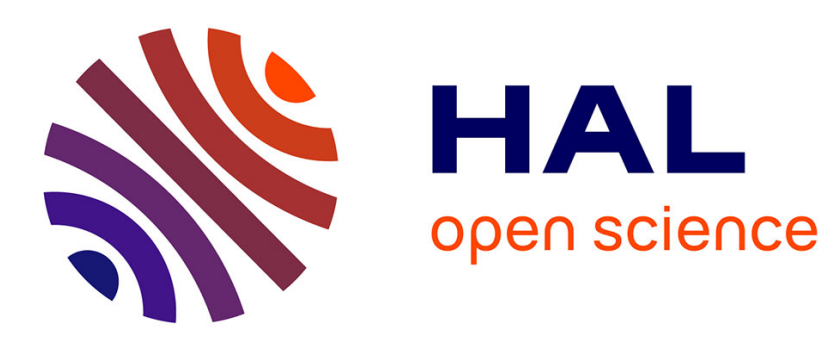

\title{
Cluster Emergence and Network Evolution: a Longitudinal Analysis of the Inventor Network in Sophia-Antipolis
}

\author{
Anne L.J. ter Wal
}

\section{- To cite this version:}

Anne L.J. ter Wal. Cluster Emergence and Network Evolution: a Longitudinal Analysis of the Inventor Network in Sophia-Antipolis. Regional Studies, 2010, pp.1. 10.1080/00343401003614258. hal00597454

\section{HAL Id: hal-00597454 \\ https://hal.science/hal-00597454}

Submitted on 1 Jun 2011

HAL is a multi-disciplinary open access archive for the deposit and dissemination of scientific research documents, whether they are published or not. The documents may come from teaching and research institutions in France or abroad, or from public or private research centers.
L'archive ouverte pluridisciplinaire HAL, est destinée au dépôt et à la diffusion de documents scientifiques de niveau recherche, publiés ou non, émanant des établissements d'enseignement et de recherche français ou étrangers, des laboratoires publics ou privés. 


\section{Cluster Emergence and Network Evolution: a Longitudinal Analysis of the Inventor Network in Sophia-Antipolis}

\begin{tabular}{|r|l|}
\hline Journal: & Regional Studies \\
\hline Manuscript ID: & CRES-2008-0206.R1 \\
\hline Manuscript Type: & Main Section \\
\hline JEL codes: & $\begin{array}{l}\text { D85 - Network Formation < D8 - Information and Uncertainty < D - } \\
\text { Microeconomics, L14 - Transactional Relationships } \mid \text { Contracts and } \\
\text { Reputation|Networks < L1 - Market Structure, Firm Strategy, and } \\
\text { Market Performance < L - Industrial Organization, O18 - Regional, } \\
\text { Economic Development, Technological Change, and Growth, R11 - } \\
\text { Regional Economic Activity: Growth, Development, and Changes < } \\
\text { R1 - General Regional Economics < R - Urban, Rural, and Regional } \\
\text { Economics }\end{array}$ \\
\hline Keywords: & $\begin{array}{l}\text { cluster evolution, network evolution, collective learning, Sophia- } \\
\text { Antipolis }\end{array}$ \\
\hline \hline
\end{tabular}

\section{$\mathbf{x}$}


Part of Special issue: Structure and dynamics of innovative networks

\title{
Cluster emergence and network evolution:
}

A longitudinal analysis of the inventor network in Sophia-Antipolis

\author{
Anne L.J. ter Wal \\ Imperial College Business School, Innovation Studies Centre, \\ Tanaka Building, South Kensington Campus, London SW7 2AZ (UK) \\ Utrecht University, Department of Economic Geography, P.O. Box 80.115, \\ 3508 TC Utrecht (Netherlands) \\ a.terwal@imperial.ac.uk
}

(Received August 2008: in revised form December 2009) 


\begin{abstract}
It is increasingly acknowledged that clusters do not necessarily exhibit networks of local collective learning. Through a case-study of Sophia-Antipolis this study investigates to what extent networks of collective learning emerged throughout the growth of the business park. A longitudinal analysis of the inventor networks of its two main sectors reveals that a local network of collective learning emerged only in Information Technology and not in Life Sciences. Through the creation of spin-offs and high-tech start-up firms the initial dominance of large multinationals decreased only in Information Technology. This suggests that small firms play an important role in establishing local networks.
\end{abstract}

JEL-codes: D85 - L14 - O18 - R11

Key words: cluster evolution, network evolution, collective learning, SophiaAntipolis 


\section{INTRODUCTION}

The business park of Sophia-Antipolis originates from the private initiative of Pierre Laffitte to turn a 'greenfield' site just off shore the Côte d'Azur into a high-tech park. Partly due to public support and marketing, high-tech activities started to be located there from the 1970s onwards. International high-tech firms, mainly from Information Technology and Life Sciences industries, that wanted to adapt their products to the requirements of the European market were attracted by favourable locational characteristics like the pleasant climate and the presence of an extensive tourist infrastructure. This implies that the 'cluster' was originally nothing more than pure co-location of high-tech firms, completely lacking a local interaction structure. This has changed through the course of time. It is often argued that Sophia-Antipolis' Information Technology sector is more and more characterized by local knowledge-based interaction among its firms and research institutes, whereas such interaction is less apparent and convincing in Life Sciences (LONGHI 1999; QUÉRÉ 2007).

This story is very much in line with important findings in the recent literature on clusters. It is increasingly agreed upon that it cannot be assumed beforehand that all firms in a cluster are involved in local networks of collective learning (GIULIANI 2007). Consequently, the constructs of clusters and networks need to remain conceptually disentangled. As VISSER (2009, p. 168/169) puts it: "Clusters refer to spatial concentration processes involving a related set of activities in which context firms may but need not cooperate". Conversely, networks refer to (...) cooperation in the form of knowledge exchange between firms and other actors that may but need not develop these links at the local or regional level." 
In other words, clusters and networks do not necessarily coincide. An important follow-up question, then, is under which conditions clusters exhibit local collective learning networks. This study examines this relationship between clusters and networks by means of a longitudinal analysis of the inventor networks in Sophia-Antipolis' two main sectors. As a cluster emerges, grows and eventually declines, the conditions under which firms and individual inventors in that particular cluster interact in networks change as well. This study takes a closer look at the introductory and growth stages of the co-evolution of clusters and networks (TER WAL and BOSCHMA 2009b). By means of a longitudinal analysis of the example case of Sophia-Antipolis, this paper thus aims to demonstrate how local networks of collective learning evolved while the cluster emerged and grew. It shows that the extent to which clusters and networks show overlap might be dependent on the nature and extent of the spatial clustering of firms in space. In so doing the paper aims to deviate from the mainstream literature of static cluster studies and to respond to the increasing need for studies that examine under which conditions local networks of collective learning emerge.

In order to accomplish these aims, the paper proceeds as follows. First, Section 2 describes how Sophia-Antipolis emerged and grew from the 1970 s onwards. This description is based on interviews with key actors at local authorities and research institutes and on secondary data sources. Then, Section 3 reconstructs the evolution of co-inventorship networks throughout these years on the basis of USPTO and EPO patent data. Co-inventorship networks are considered as a proxy for local networks of collective learning. Section 3 also discusses the limitations the use of patent data has for the 
analysis of the evolution of these networks. In Section 4 these networks are analyzed with social network analysis techniques, testing propositions on how they evolved in terms of their geographical orientation, connectivity, path length and clustering coefficient. By looking at these four dimensions this study claims to demonstrate if and how an integrated network of collective learning emerged in the two main sectors of Sophia-Antipolis: Information Technology and Life Sciences. Finally, Section 5 concludes.

\section{THE EVOLUTION OF THE CLUSTER OF SOPHIA-ANTIPOLIS}

Nowadays it is widely agreed upon that it is very hard to create clusters or innovation systems in an artificial way through planning or regional policy (MARTIN and SUNLEY 2003). Cohesive clusters and innovation systems are mostly considered as being the result of 'natural' developments, which at best can be facilitated or further stimulated by policy initiatives. Sophia-Antipolis constitutes a quite unique example of a cluster in that it is to a large extent created artificially. This section aims to describe the emergence and growth of Sophia-Antipolis from a qualitative perspective. It is based on interviews with key actors within the political and academic spheres of Sophia-Antipolis. To be precise, in October 2006 interviews were conducted at the four key public and semi-public authorities that are involved in economic development policy in Sophia-Antipolis ${ }^{i}$ and with the representatives of knowledge valorisation of the four main research institutes in the field of Information Technology and Life Sciences within Sophia-Antipolisii.

\section{Emergence}


Although Sophia-Antipolis is an artificially created cluster, the starting point was not in the public sphere. The very beginning of Sophia-Antipolis stems from the private initiative of Pierre Laffitte (Member of the Board of the "Ecole Nationale Supérieure des Mines de Paris") in the late 1960s, early 1970s. He envisioned "a City of Science, Culture and Wisdom" in the South of France where its participants would be attracted by the so-called Sunbelt effect, i.e. the pleasant climate and other comfortable living conditions. He acquired a forested plain between Antibes and Valbonne at the French Côte d'Azur in order to realise his plans. This area can be viewed upon as a 'vacant space' or 'greenfield site', lacking any industrial or university tradition (LONGHI 1999). The first buildings arose in 1972.

The initial project ended up soon in severe budgetary problems. The high costs of providing the necessary infrastructure did not outweigh the benefits that accrued from the initiative. However, being interested to diversify the economy of the Côte d'Azur from mere tourism, the local public authorities supported the initiative already in an early stage and soon the project transformed completely from a private initiative into a public one. With this transformation the focus of the project shifted more explicitly towards hightech activities, since this type of activity could easily complement tourism without causing negative externalities (e.g. pollution) to the region's main economic resource (QUÉRÉ 2002, 2007).

From the late 1970s, the agglomeration of firms and employment in the park started (see figure 1). This can be considered the first phase of development of the business park of Sophia-Antipolis and consisted mainly of the entry of non-European firms that wanted to open an R\&D facility in which 
they could adapt their products to the specific requirements of the European market. Although it did not result from an explicit strategy, particularly Information Technology firms - and to a lesser extent firms in the Life Sciences and Energy industries - turned out to be attracted to SophiaAntipolis (LONGHI and QUÉRÉ 1997).

Three main reasons can be held responsible for this successful take-off (QUÉRÉ 2002). First, there are some structural characteristics of the region that made the Côte d'Azur, in itself a region without any prior industrial tradition, an attractive region for foreign investment. These characteristics included the pleasant climate and other natural conditions, the presence of an extensive tourist infrastructure, including an international airport, but also conference rooms, hotels etc. The newly arrived firms could benefit easily from this physical infrastructure. Second, but not less importantly, the local authorities developed an explicit and active advertising strategy to promote Sophia-Antipolis as a high-tech business park, especially in the United States. A third factor that stimulated the increasing concentration of firms in SophiaAntipolis was the explicit decentralisation policy the French government exerted during the 1970s in order to promote economic development outside the traditional booming regions (LONGHI 1999). In this light the early arrival of France Télécom in the area can be seen as a crucial development. France Télécom provided a modern and efficient fibre-optical network that worked out as an important pull factor for other Information Technology firms, which could use this advanced infrastructure base to develop applications readily and efficiently (LAZARIC et al. 2008). 


\section{\#\#\# FIGURE 1 ABOUT HERE \#\#\#}

In short, as is often the case in the early emergence of clusters (ARTHUR 1994; MASKell and MALmberg 2007), the initial concentration of firms in Sophia-Antipolis has shown to depend considerably on serendipitous factors. First of all, the visionary pioneer Pierre Laffitte happened to be located in the region. Moreover, the attraction of international firms' subsidiaries to SophiaAntipolis on the basis of its pleasant climate is at least remarkable, especially when considering the completely lacking industrial tradition in the region and the wide set of alternative locations across Europe. The subsequent take-off of the growing concentration of firms, however, has been much less dependent on chance factors. The active promotion strategy and the creation of the first agglomeration advantages - for instance related to France Télécom's internet infrastructure - further stimulated the concentration of firms in Sophia-Antipolis. Or as BRENNER (2004) puts it, local self-augmenting processes were put in place that reinforced the initial forces towards spatial clustering.

\section{$\underline{\text { Intermediate crisis }}$}

At the end of the 1980s and beginning of the 1990s the growth process in terms of number of firms and employment started to slow down, particularly in Sophia-Antipolis' main sector of Information Technology. The business park of Sophia-Antipolis started to suffer from a number of important shortcomings. First, it lost competitiveness relative to other regions concerning the attraction of international companies, since those companies changed and expanded 
their set of location requirements and got a deeper knowledge of the alternatives. Ireland and Scotland, for instance, could provide cheaper qualified labour in comparison to Sophia-Antipolis, while central cities like Paris and London offered a closer proximity to customers and/or financial and administrative services (QUÉRÉ 2002). Whereas Sophia-Antipolis was highly competitive in the 'globalisation regime' of the 1980s, the park did not keep pace with the changing nature of globalisation in the 1990s. In the 1980s companies were to a large extent vertically integrated and firm location decisions were mainly based on costs and the presence of facilities. In the 1990s, however, these decisions started to be based more on locational features that might stimulate innovation (LONGHI 2002; LAZARIC et al. 2008), since high-tech firms acknowledged more the importance of knowledge from outside the company for reaching innovation. As a consequence of this shift in locational preferences, the growth of the number of companies in SophiaAntipolis stagnated and some of the established companies even decided to relocate to other areas (QUÉRÉ 2002).

A second, related shortcoming concerns Sophia-Antipolis as a cluster of innovative activity. Beside the fact that through the course of time many companies had been attracted on site that did not focus explicitly on R\&D, innovation in Sophia-Antipolis took place exclusively within the boundaries of the firms. In other words: until the end of the 1980s at least, Sophia-Antipolis was not a cluster in the 'Porter' sense, where innovations accrued through interaction of related firms. By contrast, it was nothing more than a concentration of firms that were co-located on the basis of a similar set of pull factors. Obviously, the local agglomeration process of related firms is a 
necessary, but insufficient condition for constituting an innovation system (LONGHI and QUÉRÉ 1997). Considering also, that most of the companies did not have their market locally, Sophia-Antipolis could be viewed upon as a compilation of highly footloose firms (QUÉRÉ 2002). In other words: SophiaAntipolis functioned as a 'satellite platform', as defined by MARKUSEN (1996), where the companies due to their international background had a wide array of international relations beyond the cluster's boundaries, whereas local interactions were almost completely absent (LONGHI 1999; LAZARIC et al. 2008).

\section{Growth}

After the crisis in the early 1990s the Information Technology and Life Sciences industry in Sophia-Antipolis show a strongly divergent pattern of development. In the Information Technology industry it is exactly the 'crisis' of the disappearing international firms that triggered important endogenous developments. The relocating international companies left a pool of highly qualified labour that to a large extent did not move along with the company, but that wanted to stay in the Côte d'Azur region. Many of those people started their own firm. Consequently, the shock of the shrinking presence of multinationals provided a stimulus for stronger locally-based growth of the park that resulted in the emergence of technologically advanced SMEs (QUÉRÉ 2007). 
This transformation from externally-driven to locally-based growth in the IT industry was further reinforced by the arrival of public and private education and research institutes in Sophia-Antipolis. Most of these institutes, like the University of Nice Sophia-Antipolis, INRIA (National Research Institute on Informatics and Automation) and CNRS (National Centre of Scientific Research), were not present on site already in the early stages of development of the park, but were established from the mid-1980s only. The same holds for the European authority on Telecommunication Standards (ETSI), which has been located in Sophia-Antipolis since 1989. Considering that generally most of the attempts to build a science park start with the location of research institutes in the park, this makes Sophia-Antipolis an atypical, 'reverse' science park (QUÉRÉ 2007). The research institutes have been attracted in the late 1980s on the basis of an explicit strategy of the national and regional authorities to promote synergies between science and industry. These synergies consist largely of building a highly qualified local labour market, but also include $\mathrm{PhD}$ students doing traineeships or research projects in firms.

These new developments mainly concerned the Information Technology industry in Sophia-Antipolis. Three important differences between the Information Technology and Life Sciences sector can be observed. First, there is a large difference between the two industries in the total number of firms that have been concentrated locally. Information Technology experienced a shift from growth led by foreign multinationals to growth mainly based on local spin-offs and high-tech start-ups. Hence, for this industry the crisis turned out to be only a relatively short interruption between the initial 
emergence of the cluster and the subsequent follow-up phase of extensive growth (see Figure 2). The period of transition from externally-driven to locally-based growth took off from the first half of the 1990s onwards and still continues nowadays. By contrast, the concentration of Life Sciences firms was not strongly affected by the crisis, but at the same time did not show an increase in the second half of the 1990s, such as in the Information Technology sector. As Figure 2 shows, the growth of the number of firms in the Life Sciences sector has always proceeded at a lower rate than in the Information Technology sector. The increase of the number of Life Sciences firms came to a hold in the 1990s. Nowadays, Information Technology firms constitute about $75 \%$ of Sophia-Antipolis' high-tech companies, whereas Life Sciences firms make roughly $13 \%$ (SYMISA 2004). Consequently, from the middle of the 1990s onwards Sophia-Antipolis specialised progressively towards Information Technologies at the relative expense of Life Sciences companies (see Figure 2) and Energy and Earth Sciences.

Second, the increasingly locally-based growth in Information Technology made this sector diversify in terms of size. Whereas the park was strongly dominated by large firms in the early stages, the changing nature of growth in the Information Technologies industry resulted in an increasing share of small- and medium sized enterprises. The Life Sciences sector, however, is nowadays still largely dominated by relatively large subsidiaries of international pharmaceutical companies such as Dow Chemical, Allergan and Sanofi-Aventis.

Third, the cognitive distance seems smaller between firms in Information Technology than in Life Science. Partly due to the presence of the 
European Telecom Standardization Institute (ETSI), most of the Information Technology firms work in segments of the same value chain (Krafft 2004). Nowadays, Sophia-Antipolis' IT sector consists of three main building blocks: infrastructure (equipments, networks and hardware), platforms (interfaces and software) and applications (including services). These three building blocks are more or less equally present in Sophia-Antipolis and are strongly related to each other (Krafft 2004). The interrelatedness of the products and services they develop positively affects the opportunities for collaboration and collective learning. This potential is increasingly perceived also by public and private stakeholders in IT in Sophia-Antipolis. An important private initiative in this respect is made by the Telecom Valley Association, which aims to map competences of agents in the park and promotes the emergence of clubs and associations in an attempt to link small firms, large firms and research institutes in the field of Information Technology (LONGHI 1999; LAZARIC et al. 2008). In the Life Science sector, however, the cognitive distance between agents seems much larger. The activities within the sector range from drugs, biotechnology and cosmetics to medical equipment and fine chemistry. Hence, the specializations among Life Sciences companies in the park differ largely and, hence, the potential for complementarities might be rather limited (LONGHI 1999).

\section{THE CO-EVOLUTUION OF CLUSTERS AND NETWORKS}

The foregoing section demonstrated that the Information Technology and Life Sciences industries within the cluster of Sophia-Antipolis show a divergent evolution path in terms of the emergence and growth of the cluster. Not only 
has the total growth of the number of firms in Information Technology been bigger, from the first half of the 1990s the growth has also been based increasingly on local spin-offs and high-tech start-ups, whereas the growth of Life Science remained dependent mainly on the growth of multinational enterprises. This paper argues that these differences in the evolution path of spatial clustering have implications for how local networks of collective learning evolve. When a cluster emerges and grows, the size and composition of its set of firms is subject to change. This has direct implications for the potential for local collective learning and can be considered the basic mechanism that couples cluster dynamics and network dynamics into a process of co-evolution. More specifically, two main mechanisms link the emergence and growth of a cluster to the evolution of its network of local collective learning.

First, the higher the local concentration of inventors active in a certain technology, the more opportunities for local collective learning emerge. A local concentration of firms doing similar things will facilitate knowing about each others' activities - and hence the potential for collective learning - at low cost (MALMBERG and MASKELL 2002). Since the total concentration of firms and research institutes is much larger for Information Technology than for Life Sciences, it is expected that a critical mass of agents for collective learning will only have been reached in Information Technology and not in Life Sciences (LONGHI and QUÉRÉ 1997; QUÉRÉ 2007).

Second, the formation of high-tech start-ups and the emergence of spin-off companies in the Information Technology sector might contribute to the emergence of a local collective learning milieu. Spin-offs and high-tech 
start-ups tend to maintain linkages with the incumbent firm, research institute or university. Spin-offs inherit capabilities from the incumbent organization (KLEPPER and SLEePer 2005) and - due to myopia (LeVINTHAL and MARCH 1993; MASKeLL and MALMBERg 2007) - tend to do relatively similar things as the incumbent firm. As a consequence, these firms have a strong potential for collective learning with the incumbent firm and its partners right from the start. Furthermore, both high-tech start-ups and spin-off firms signal the presence of a highly qualified and relatively mobile labour market. Mobility of highly qualified personal across firms is an important channel of unintended, though valuable forms of collective learning (ALMEIDA and KoGUT 1999). The research institutes in Information Technology present on site play a key role in the creation and maintenance of this labour market.

Hence, based on the differences in the clustering process of Information Technology and Life Sciences industries differences are expected in whether and to what extent collective learning practices have emerged in the two main sectors of Sophia-Antipolis. For the Information Technology industry one expects to observe a trend towards the emergence of a local collective learning milieu throughout the evolution of Sophia-Antipolis, though particularly when the growth regime switched from being mainly externallydriven to mainly locally-based in the middle of the 1990s. For the Life Sciences industry any such trend towards the emergence of a local collective learning milieu is not expected to be observable.

Detecting local collective learning 
The evolution of the network of collective learning in Sophia-Antipolis is assessed through an investigation of co-inventorship networks. These networks capture two important dimensions of a local network of collective learning. First, a co-inventorship network is a representation of the local structure of intended knowledge exchange between individual actors (EJERMO and KARLSSON 2006). The fact that multiple inventors are mentioned on a single patent document is a clear sign of knowledge-intensive team work, irrespective of the fact whether or not the inventors mentioned on the patent worked for the same firm or research institute at the time of innovation. Second, a co-inventorship network has a strong social connotation. People who have worked together on the same innovation project (BRESCHI and LISSONI 2003) or who have worked for the same firm at the same time (CASPER 2007) have a social relationship that tends to endure over time, even when they move to another firm or even to another region (AGRAWAL et al. 2006). These types of interpersonal networks are considered an important channel for the diffusion of technological knowledge (ZANDER and KOGUT 1995; DAHL and PEDERSEN 2004). BRESCHI and LISSONI (2003) and SINGH (2005) demonstrated that the fact that knowledge spillovers tend to be localized, is mainly due to the localized nature of social networks. The underlying network of co-inventorship relations - interpreted as a social network among engineers - could very well explain the localized pattern of patent citations. The presence of a cohesive network of this kind in a cluster with indirect relationships between inventors in a network - is of utmost importance for knowledge to circulate locally (NoOTEBOOM and KLEIN- 
WoOLTHUIS 2005) and can be considered a clear signal for the existence of a local collective learning milieu.

This study considers four different properties of co-inventorship networks to assess the presence of local collective learning. Among these density is deliberately disregarded, since density is highly sensitive to network size and cannot be compared across networks of unequal size. Almost as a rule density declines with network growth, since the increase of the number of possible links is quadratic when the number of nodes increases linearly (FRIEDKIN 1981). Also path length and clustering coefficient are sensitive to size. In contrast to density, however, these properties can be analysed longitudinally by comparing the actual values to the values one would expect in random networks of equal size and density.

The first property that is considered in this study is the geographical orientation of the network of inventors. Since all inventors with whom local inventors have co-invented are included, the network also encompasses all linkages from local inventors to non-local (national or international) inventors. Bearing in mind the original international character of the business park a strong international orientation can be expected in the emergence and early growth stages for both sectors. Due to the change from externally-driven to locally-based growth in Sophia-Antipolis' Information Technology sector one can expect to observe an increase in interaction between local inventors for this sector only. The propositions are formulated as follows:

Proposition 1a: In Information Technology the inventor network has become more locally oriented throughout the growth of Sophia-Antipolis. 
Proposition 1b: In Life Sciences the inventor network has not become more locally oriented throughout the growth of Sophia-Antipolis.

Here the focus is primarily on the emergence of local collective learning, although it is acknowledged that it is extremely important for a cluster to be linked to the outside world as well. The importance of local interaction within a cluster should clearly not be overstated (WATERS and LAWTON-SMITH 2008). An 'external gaze' to world that ensures the inflow of codified knowledge about scientific discovery and technological advancement in the wider industry is of utmost importance for a cluster and its firms to remain competitive (AMIN and COHENDET 1999; ASHEIM and ISAKSEN 2002).

A second network property that signals local collective learning is the cohesive nature of the inventor network. The connectivity of a network is expressed as the proportion of node pairs in a network that can reach one another by virtue of the existence of a network path. Hence, a network with high connectivity allows knowledge not only to flow through direct linkages, but also through indirect linkages (NoOtEBoom and KLEIN-WOOLTHUIS 2005). FLEMING and FRENKEN (2007) demonstrated for inventor networks in Silicon Valley and Boston that through the course of time multiple unconnected substructures in these local networks joined together to form a giant, interconnected component. In Sophia-Antipolis it is expected that the locallybased growth in the growth stage of the Information Technology industry has stimulated the emergence of a network with high connectivity in this sector, whereas - by contrast - such trend is not expected in Life Sciences. When looking to the evolution of connectivity in a network, it needs to be 
acknowledged that fast growing networks will find relative difficulty to retain high levels of connectivity in comparison to constantly or slowly growing networks; due to the fact that the number of potential linkages grows in quadratic terms in a linearly growing network. Since Information Technology in Sophia-Antipolis is characterized by a much higher number of entrants than the Life Science sector, the tendency towards more connectivity might be partly counteracted by the growth of the network in terms of number of inventors. CASPER (2007), however, found in his study of the inventor network in the San Diego biotech cluster that connectivity remained high, notwithstanding the massive growth of the network. Therefore, the expectations concerning connectivity are formulated as follows:

Proposition 2a: In Information Technology connectivity of the inventor network has increased throughout the growth of Sophia-Antipolis.

Proposition 2b: In Life Sciences connectivity of the inventor network has not increased throughout the growth of Sophia-Antipolis.

The third and fourth properties of a local collective learning network relate to the presence of a small world structure (WATTS and STROGATZ 1998). A small world structure combines two network properties that tend to be beneficial for learning: structural holes and social capital (VERSPAGEN and DUYSTERS 2004; CowAN et al. 2006). Structural holes refer to the absence of a link between two partners of a node. If present, that link would produce a closed triangle in which three nodes are all directly connected to one another. In a network rich in structural holes certain nodes form the bridge between otherwise 
unconnected or weakly connected parts of a network (BURT 2004). These bridges ensure the inflow of novel information into denser parts of the network. As a result, structural holes are held to be important for avoiding situations of cognitive lock-in (GLÜCKLER 2007). The presence of structural holes leads to a short average path length between actors in a network, as a consequence of which knowledge can flow easily throughout the network as a whole. On the other hand, the dense local structures with many redundant ties that also characterize small worlds are generally interpreted as a sign of social capital (COLEMAN 1988; WALKER et al. 1997). The presence of dense local structures - apparent in a high average clustering coefficient - facilitates trust-based and frequent exchange of high-quality information among the actors involved. A small world network that combines a high clustering coefficient with a short path length, then, combines the advantages of efficiency and embeddedness. Accordingly, FLEMING et al. (2007) demonstrated that a regional small world structure positively affects regional innovativeness. In this study both a short path length and a high clustering coefficient are viewed as important characteristics of a local collective learning milieu. Thus, one expects to observe a trend towards shorter path lengths and increasing clustering coefficients only in Information Technology, and not in Life Sciences:

Proposition 3a: In Information Technology a trend towards decreasing average path length of the inventor network can be observed throughout the growth of Sophia-Antipolis. 


\begin{abstract}
Proposition 3b: In Life Sciences a trend towards decreasing average path length of the inventor network can be observed throughout the growth of Sophia-Antipolis.
\end{abstract}

Proposition 4a: In Information Technology a trend towards an increasing clustering coefficient of the inventor network can be observed throughout the growth of Sophia-Antipolis.

Proposition 4b: In Life Sciences a trend towards an increasing clustering coefficient of the inventor network cannot be observed throughout the growth of Sophia-Antipolis.

\title{
4. METHODOLOGY
}

Patent documents have come to be a rich source of information on knowledge production and innovation activity. Although it can be easily argued that patents do not capture the whole spectrum of innovation activity and, therefore, patent documents are not the ideal source of information in that respect, the highly detailed information they contain provides ample opportunities for studying the geography of innovation activity. For instance, patents - which are not equally distributed in space - are widely used in economics as a measure of regional knowledge production (Acs et al. 2002). Moreover information on patent citations is used for tracing knowledge spillovers across firms and to investigate the role of geographical or other forms of proximity in their spatial pattern.

A relatively new use of patent data is their application to the reconstruction of cooperation networks back in time (see for instance BRESCHI 
and LISSONI 2003; CANTNER and GRAF 2006). In the same vein, this paper will use patent data to reconstruct the networks of collective learning in which inventors from Sophia-Antipolis have been involved.

\section{Data}

Two differences sources of patent data are used to reconstruct the evolution of co-inventorship networks: patents from the European Patent Office (EPO), available for the period from 1978 till 2002, and American (USPTO) patent data from 1975 till 1999 (HALL et al. 2001). The use of multiple data sources allows for a reliable analysis of trends in the evolution of the networks, since the network properties that signal local collective learning can be compared across the two types of networks. In both cases the patents have been dated on the basis of the application date - as opposed to the granting date - since this date is closest to the time the invention was created.

Both for EPO and USPTO data the patents were selected on the basis of the inventor address. Taking the inventor address as the selection criterion is an appropriate and commonly applied method for allocating patents to the geographical origin in which the innovation has been factually developed, as long as the spatial unit of analysis is not too small (i.e. not smaller than a labour-market area). The underlying reason is that patents developed by a subsidiary of a multi-establishment firm generally tend to be assigned to the headquarters, which are possibly located in a different region. The province of Alpes-Maritimes that surrounds Sophia-Antipolis has been taken as its labour market area. Thus, for the purpose of this study all patents with at least one inventor resident in the study area were retrieved from the larger EPO and 
USPTO datasets. Beside all local inventors these subsets of patent data also contain information about all non-local inventors they are connected to. In that way, it is possible to compare the extent to which the cooperation takes place within the local system with the extent to which the system and its actors are opened up to 'the external world' by means of connections to inventors outside the local system.

\section{\#\#\# TABLE 1 AND FIGURE 3 ABOUT HERE \#\#\#}

Table 1 shows the number of EPO and USPTO patents on which the reconstruction of the networks is based. Patents have been allocated to the Information Technology, Life Sciences or Miscellaneous categories on the basis of the main technology class mentioned on the patent document. For the EPO patents the OST-INPI/FhG-ISI technology nomenclature as developed by SCHMOCH et al. (2003) was used to recode the patent IPC technology classes into sector codes. Which sectors have been allocated to the IT and Life Sciences industries is explained in Appendix 1. For the USPTO patents use was made of the classification as proposed by Hall et al. (2001); the two-digit subcategories that constitute the Information Technology and Life Sciences industries are specified in Appendix 2. Both for EPO and USPTO patents Information Technology has been defined in broad terms, including also related fields in Electronics, such as semiconductors.

As Figure 3 and Table 1 show the patent portfolio of Alpes-Maritimes has always been dominated by the Information Technology and Life Sciences sectors, both for EPO and USPTO patents. Since these two sectors are 
mainly concentrated in Sophia-Antipolis, the dominance of these sectors in the total number of patents from Alpes-Maritimes justifies the choice of this surrounding province as the spatial scale of analysis. However, as Table 1 shows, the total number of patents on which the analyses - covering a period of approximately 20 years - are based is rather limited. Hence, it needs to be acknowledged that the networks that are constructed on the basis of patent data are not a full representation of local collective learning practices. Cooperation activity that did not lead to a patent is not captured by the methodology. This implies, for instance, that more informal collaborations as well as unsuccessful collaborations are absent in patent data. More importantly, Information Technology firms differ in their tendency to protect their innovations by patents. Especially software producers have a relatively low tendency to patent (BESSEN and HUNT 2007) and, consequently, will be underrepresented in patent data. Also smaller firms and research institutes tend to be underrepresented in patents. These limitations need to be borne in mind when interpreting the network analysis results.

Figure 3 also shows the number of patents and inventors in 5-year moving windows for each of the data sources. In line with the general trend towards more patenting, these figures show a nearly constant increase in the number of patents. Strikingly, the crisis in the first half of the 1990s in IT, as reported in Section 2, is visible in a decreasing growth rate of the number of patents. After this crisis, in the second half of the 1990s, one can observe a strong increase in this growth rate. The increased share of IT-patents in total number of regional patents confirms this observation. 


\section{Network reconstruction}

Co-inventorship networks are used to analyse the emergence of local collective learning in Sophia-Antipolis. In these networks individual inventors are linked when they have worked together on a patent. Making use of information at two distinct levels, a co-inventorship network is a one-mode projection of a two-mode (or bipartite) network between patents and inventors. This study deliberately takes the inventor - and not the firm - as its level of analysis. A firm-level network analysis based on patent data is often problematic, since patents tend to be assigned exclusively to large companies, even when smaller firms or research institutes have (also) been involved. As a consequence, when tracing inter-organizational links in this way many collaboration linkages will not be revealed (TER WAL and BOSCHMA 2009a). However, a network analysis at the individual inventor level as employed in this study largely compensates for this shortcoming; the individual inventors of small firms or research institutes will be mentioned on the patent document, also in case the patent is in possession of a private firm, which has either bought the patent or was involved as a cooperation partner. In fact, it is the mobility of inventors across companies and the involvement of inventors from SMEs and research institutes that potentially link together groups of inventors that work for different local firms. Consequently, this paper builds on the premise that a cohesive and integrated local co-inventorship network signals the presence of a local learning that exceeds firms' boundaries.

For that purpose inventor-level networks are generated in two different ways. The two methods differ from each other in the assumptions they make 
about how long links between inventors persist. This kind of assumption needs to be made, since no information on the dissolution of links can be extracted from patent data. In the first procedure, networks were built using a 5-year moving window procedure. This implies that a network of a particular year contains all co-inventorship linkages of that year and the preceding four years. The networks that have been generated this way are used to plot trends in terms of the geographical orientation and the fragmentation of the network. The second procedure concerns a cumulative network over the complete period of investigation. The assumption here is that social links between inventors persist over time (AGRAWAL et al. 2006), although it needs to be acknowledged that people might exit the region or the industry. Whereas the networks generated by the five-year moving window procedure could be considered more as an approximation of structure of the existent interpersonal knowledge flows and acts of cooperation in a region (EJERMO and KARLSSON 2006), the cumulative inventor network is more an indication of the ever growing underlying social network that potentially functions as a network through which relevant innovation-related knowledge can flow (BRESCHI and LISSONI 2003). Hence, the networks generated with the five-year moving window procedure will be used for the analysis of the cooperative structure of collective learning, whereas analysis of small world properties will be based on the cumulative inventor network.

\section{Measures of local collective learning}

As explained before, the evolution of the inventor networks in Sophia-Antipolis and the emergence of collective learning practices are assessed on the basis 
of four different network properties. A series of propositions formulates the expectations of how these properties evolve over time for both sectors.

The first network property is the geographical orientation of inventors in the network. Both the EPO and USPTO networks encompass all local actors and all non-local actors with whom they are linked. Therefore a distinction is made between network relationships at three spatial scales: local-local, localnational and local-international interaction.

The second property is network connectivity or, inversely, network fragmentation. As GIULIANI (2007) showed it should not be assumed beforehand that knowledge networks in clusters are pervasive. Network fragmentation can be measured in various ways. First, the fragmentation index is defined as the proportion of nodes in the network that cannot reach other. This is the case when two nodes belong to different, unconnected components of the network. The second measure of connectivity is the share of the network's main component or largest components in terms of number of nodes or number of links (see also CANTNER and GRAF 2006; CASPER 2007; FLEMING and FRENKEN 2007). A component in a network is any subset of nodes between which a direct or indirect network path exists. The largest component of connected nodes in a network is referred to as the Main Component. The fragmentation index and the share of the main component will be computed on the networks generated with 5-year moving window procedure. As argued before, these are the best approximation of the evolution of actual collective learning practices in Sophia-Antipolis.

The third property is the average path length, computed on the Main Component of the cumulative inventor network. An average path length that is 
similar to the value one could expect in a random network of equal size and density signals small world properties (WATTS and STROGATZ 1998). Therefore the Path Length ratio is calculated in order to indicate the extent to which the observed path length differs from the value expected in a comparable random network. The more the PL-ratio exceeds 1.0, the stronger the small world nature of the network (UZZI and SPIRO 2005). Since an inventor network as studied here is a one-mode projection (at the inventor level) of a two-mode network (of patents and inventors), the Path Length Ratio is calculated as follows (NEWMAN et al. 2001) iii:

$$
\begin{aligned}
& P L_{\text {actual }}=\frac{1}{n \cdot(n-1)} \cdot \sum_{i, j} d\left(v_{i}, v_{j}\right) \\
& P L_{\text {random }}=\frac{\ln (n)}{\ln (\mu \cdot v)} \\
& P L_{\text {ratio }}=\frac{P L_{\text {actual }}}{P L_{\text {random }}} \\
& d\left(v_{i}, v_{j}\right)=\text { geodesic distance between node i and } \mathrm{j} \\
& n=\text { number of nodes in the network } \\
& \mu=\text { average number of inventors per patent } \\
& v=\text { average number of patents per inventor }
\end{aligned}
$$

A high clustering coefficient is the fourth property of the network of collective learning that is considered. The clustering coefficient is defined as the extent to which the partners of a node are connected among them. At the aggregate level of a network, the clustering coefficient takes the average clustering coefficient across all nodes. An alternative way of calculating the actual clustering coefficient of a network is taking the number of closed triangles (completely connected triads) over the number of 'potential' triangles (a set of three nodes connected by at least two links). The CC ratio compares the 
actual clustering coefficient to the clustering coefficient that can be expected in a random network of the same size and density. The further this ratio departs from 1.0, the more the network is of a small world nature (Uzzi and Spiro 2005). The formulas for calculating the CC ratio are as follows (NEWMAN et al. 2001) iv:

$$
\begin{aligned}
& C C_{\text {actual }}=\frac{3 \cdot \text { number of triangles on the graph }}{\text { number of connected triplets of nodes }}=\frac{\text { number of triangles with at least } 3 \text { legs }}{\text { number of triangles with at least } 2 \text { legs }} \\
& C C_{\text {random }}=\frac{M v^{3}}{N v^{2}\left(\mu^{2}+\mu\right)}=\frac{1}{\mu+1} \\
& C C_{\text {ratio }}=\frac{C C_{\text {actual }}}{C C_{\text {random }}} \\
& M=\text { number of patents } \\
& N=\text { number of inventors } \\
& \mu=\text { average number of inventors per patent } \\
& v=\text { average number of patents per inventor }
\end{aligned}
$$

\section{RESULTS}

In Section 3 propositions were formulated related to four network properties that detect the emergence of local collective learning: geographical orientation, connectivity, average path length and clustering coefficient. It was argued that only in Information Technology a trend towards local collective learning is likely to be observed during the growth of the park. Not only has growth in IT - in comparison to Life Sciences - been larger in numerical terms, it also has changed in nature; whereas growth initially was dependent on multinational firms in both sectors, growth of the IT sector became increasingly based on local spin-offs and start-ups in the 1990s. The argument was made that the changing nature of the growth process in IT 
might have induced the emergence of a local collective learning milieu for this sector of the business park. Consequently, a trend towards more local-local interaction, stronger connectivity, shorter path lengths and higher clustering coefficient is expected to be observed for the inventor network in SophiaAntipolis' Information Technology sector, whereas such trends towards the emergence of local collective learning milieu are expected not to be observed in Life Sciences.

\section{Geographical orientation}

Figure 4 shows that marked differences can be observed in the geographical orientation of the Information Technology and Life Sciences inventor networks (see figure 4). In the IT industry the total number of links is increasing rapidly over time. However, the number of local linkages only increases in absolute terms; over the observation period the share of local-local linkages in all coinventorship linkages declines from roughly 80 percent to 60 percent. SophiaAntipolis' Information Technologies industry is characterized by a strong connection to the outside world, with the extent of local-international interaction strongly increasing from the middle of the 1990s onwards. Hence, there is no support for proposition 1a: the growth of local-local interaction is clearly counteracted by increased interaction with international partners, as a consequence of which the relative share of local interaction has not increased over time.

The Life Sciences industry shows a different picture. Most striking is the relative limited total number of links and its moderate growth rate over time. Even when bearing in mind the lower total number of patents in Life 
Sciences, the total extent of inventor interaction is remarkably lower than in Information Technology (figure 5). The share of local-local interaction is also consistently lower in Life Sciences than in IT over the entire observation period and for both data sources. Also in Life Sciences, however, a trend towards more international interaction can be observed from the middle of the 1990s onwards. However, no clear trend concerning local-local interaction can be depicted for Life Sciences: in the EPO-based network the relative share of local-local interaction is clearly decreasing over time, whereas the USPTO network shows a slightly increasing share of local-local interaction. Given that no consistent trends (other than increasing local-international interaction in the 1990s) can be observed, there is support for proposition $1 \mathrm{~b}$ that expressed the absence of a trend towards more local-local interaction.

\section{\#\#\# FIGURES 4 AND 5 ABOUT HERE \#\#\#}

\section{$\underline{\text { Connectivity }}$}

Connectivity has been plotted in two ways. First, the fragmentation index measures the proportion of nodes that cannot reach each other. The second measure is the share of the Main Component - the largest set of interconnected nodes - and the Top-5 components in the total number of nodes in the network. 
The fragmentation index is high for both industries. For Information Technology an increase in connectivity - i.e. a declining fragmentation index and an increasing share of the Main Component - is observed at the turn of the 1980s and 1990s (figure 6). A closer look to the patents of this period reveals that the dominance of large firms (like Texas Instruments and IBM) in the total numbers of patent was relatively high in these years. This results in relatively large groups of interconnected inventors for both of these companies, causing a decline in fragmentation. Through the course of the 1990s one can observe a strong decrease in connectivity in IT. This decrease is related to the growth of the network in terms of inventors (and the exponential growth of the number of dyads), which makes it more difficult to retain high levels of connectivity. However, unlike the network of the San Diego Biotech cluster studied by CASPER (2007), the connectivity of the IT inventor network in Sophia-Antipolis cannot keep pace with its strong growth in these years. Hence, proposition $2 a$ is not supported. The inventor network in Life Science shows very constant levels of connectivity through time, both in the EPO- and USPTO-based networks. Although the inventor network in Life Science grows slightly over time, and hence it is difficult to prevent a decline in connectivity, a trend towards increasing connectivity definitely cannot be observed. Hence, there is support for proposition $2 b$.

\section{Path Length}

Proposition $3 \mathrm{a}$ and $3 \mathrm{~b}$ formulated the expectation that a trend towards shorter average path length (as compared to the value of a random network of equal size) to be observed in Information Technology, and not in Life Sciences. 
Figure 7A shows the Path Length Ratio, calculated on the main components of the EPO inventor networks, for both industries. The Ratios are reported as soon as the Main Component's size exceeds 30 .

\section{\#\#\# FIGURE 7 ABOUT HERE \#\#\#}

The more the PL-ratio approximates 1.0, the more the path length is comparable to the path length in a random network and, hence, the easier knowledge flows through the network. In Information Technology there is a clear trend towards shorter path lengths. This is an important signal for the emergence of a local collective learning milieu: average path lengths get shorter when links are built that form a shortcut between dense substructures in a network. These links allow information to flow more easily from one side of the network to the other. Hence, the core of inventors in Information Technology gets a more coherent and efficient structure of interaction over time. In Life Science the opposite trend can be observed: the PL-ratio moves away from 1.0 over time. This happens when new links added to the network do not form shortcuts between distant parts of a network, but are instead reinforces the prior existing, dense substructures of a network. Hence, in Life Sciences no trend towards a coherent and efficient structure of core inventors can be observed. Thus there is strong support for propositions $3 \mathrm{a}$ and $3 \mathrm{~b}$.

\section{Clustering coefficient}

Proposition $4 \mathrm{a}$ and $4 \mathrm{~b}$ formulated the expectation that the CC-ratio would decline over time in IT, whereas such trend would not be observed in Life 
Sciences. Figure 7B shows that a trend towards decreasing clustering coefficients cannot be observed in neither of the two sectors. For both industries the observed clustering coefficients are much lower than could have been expected in random bipartite networks of the same size. This implies that within-team clustering is high; due to the two-mode nature of the network all inventors mentioned on a single patent form a clique in the network. By contrast, between-team clustering is lower than could have been expected at random (UzZl et al. 2007). Hence, there is no trend towards a small world structure in terms of clustering coefficients. Therefore, there is no support for proposition $4 \mathrm{a}$ and full support for proposition $4 \mathrm{~b}$.

In synthesis, the longitudinal analysis of inventor networks revealed marked differences between Information Technology and Life Sciences in Sophia-Antipolis. A local collective learning milieu has evidently always been non-existent in Life Science; none of the network properties investigated signalled a trend towards the creation of a local collective learning milieu. For the case of Information Technology the results are less straight forward; some network properties point toward a slight trend of an emerging local collective learning milieu. Even though the inventor network in IT remains fairly fragmented, the decrease in path length signals the creation of shortcuts that interlink sub-groups of inventors across the business park. It is particularly these shortcut links that form an essential element of an integrated and cohesive network of local collective learning, connecting inventors from various organizations and sub-disciplines. The differences across Information Technology and Life Sciences suggest that small local start-up companies and spin-offs play a crucial role in establishing this kind of links. 


\section{CONCLUSION}

Starting from the observation in the literature (e.g. GIULIANI 2007) that clusters do not necessarily exhibit a cohesive local network of collective learning, this paper addresses the question under which conditions these networks emerge within clusters. By doing a longitudinal case study of the cluster of SophiaAntipolis, this study aims to shed light on the question how differences in the evolution path of spatial clustering can have implications for the evolution of local networks of collective learning. In order to do so, this paper presented a longitudinal case study of the cluster of Sophia-Antipolis at the French Côted'Azur in which the co-evolution of spatial clustering and networks of collective learning were reconstructed.

Sophia-Antipolis is one of the archetypes of successful European hightech clusters that to a large extent have been created artificially. Through the course of time the cluster has progressively specialized towards Information Technology and, to a lesser extent, Life Sciences. Whereas the growth of firms in Information Technology has become stronger based on local spin-offs and high-tech start-ups from the early 1990s, the Life Sciences Sector in Sophia-Antipolis does not grow any longer and is still dominated by relatively large subsidiaries of multinational firms.

On the basis of a longitudinal analysis of patent-based networks this paper has shown that Information Technology and Life Sciences strongly differ in the way in which their networks of individual inventors evolved over time. Throughout the emergence and growth of the business park a slight trend towards the emergence of collective learning could be observed in 
Information Technology. Even though the network of inventors remains fairly fragmented, the decrease in average path length signalled the emergence of a more coherent local network over time, in which shortcuts exist that interlink dense subgroups of the network across the business park. It is argued that the shift towards growth based on local spin-offs and high-tech start-ups in Information Technology has been an important factor that enabled these developments. Inventors from spin-off and start-up firms might perform a key role in interconnecting inventors across organizational and disciplinary boundaries. By contrast, in Life Science no trend towards the emergence of a local collective learning milieu could be observed. The inventor network has always been strongly outward oriented, highly fragmented, with long path lengths and low clustering coefficients. Likewise, the absence of local spin-off and start-up firms in Life Sciences might have been a key obstacle for the emergence of a collective learning milieu in Life Sciences.

These outcomes have two important implications. First, the outcomes of this study suggest that the extent to and the way in which firms get concentrated locally highly affect the structure of the local inventor network in a cluster. The absence of any detectable form of local collective learning in Life Sciences demonstrates that geographical proximity is not a sufficient condition for local collective learning to take place. In IT, the bigger total concentration of firms and the locally-based nature of its growth in more recent years appear to have been necessary conditions for local collective learning to emerge. The results suggest that high-tech start-ups and spin-off firms play an important role in establishing local collective learning. 
Second, this study demonstrates the emergence of a local collective learning milieu is a very incremental and long-lasting process, which in the case of Information Technology in Sophia-Antipolis has taken about 20 years. It has only been since the growth regime changed from the being the result of newly arriving foreign multinationals to a growth mainly based on local spinoffs and high-tech start-ups in the early 1990s that collective learning practices started to emerge. And even then the local network of collective learning remains fairly fragmented; it is evident that the potential for local collective learning in Information Technology still is far from being exhausted.

\section{ACKNOWLEDGEMENTS}

I would like to thank the VolkswagenStiftung for funding this research. Special thanks go to Loïc Coutures for his assistance during the interviews and to Jean-Luc Gaffard for hosting me for several months at the OFCE-DRIC in Sophia-Antipolis. Furthermore I would like to thank Ron Boschma, Koen Frenken, and Michel Quéré for their supervision and helpful suggestions to earlier versions of the paper. This paper has greatly benefitted from being presented at workshops of the DIME Working Package 2.3. 


\section{REFERENCES}

Acs Z. J., ANSElin L. and VARgA A. (2002) Patents and innovation counts as measures of regional production of new knowledge, Research Policy 31, 1069-85.

Agrawal A., Cockburn I. and McHale J. (2006) Gone but not forgotten: knowledge flows, labour mobility and enduring social relationships, Journal of Economic Geography 6, 571-91.

AlmeidA P. and Kogut B. (1999) Localization of knowledge and the mobility of engineers in regional networks, Management Science 45, 905-17.

AmIN A. and COHENDET P. (1999) Learning and adaptation in decentralised business networks, Environment and Planning D-Society \& Space 17, $87-104$.

ARTHUR W. B. (1994) Increasing returns and path dependence in the economy, Ann Arbor: University of Michigan Press.

ASheim B. T. and ISAKSEN A. (2002) Regional Innovation Systems: the integration of local 'sticky' and global 'ubiquitous' knowledge, Journal of Technology Transfer 27, 77-86.

BESSEN J. and HUNT R. M. (2007) An empirical look at software patents, Journal of Economics and Management Strategy 16, 157-89.

BRENNER T. (2004) Local industrial clusters: existence, emergence and evolution, London/New York: Routledge.

BRESCHI S. and LISSONI F. (2003). Mobility and social networks: local knowledge spillovers revisited: CESPRI, Working Paper no. 142. 
BuRT R. S. (2004) Structural holes and good ideas, American Journal of Sociology 110, 349-99.

CANTNER U. and GRAF H. (2006) The network of innovators in Jena: an application of social network analysis, Research Policy 35, 463-80.

CASPER S. (2007) How do technology clusters emerge and become sustainable? Social network formation and inter-firm mobility within the San Diego biotechnology cluster, Research Policy 36, 438-55.

Coleman J. S. (1988) Social capital in the creation of human capital, American Journal of Sociology 94, 95-120.

COWAN R., JONARD N. and ZIMMERMANN J. B. (2006) Evolving networks of inventors, Journal of Evolutionary Economics 16, 155-74.

Dahl M. S. and Pedersen C. $\varnothing$. R. (2004) Knowledge flows through informal contacts in industrial clusters: myth or reality?, Research Policy 33, 1673-86.

EJERMO O. and KARLSSON C. (2006) Interregional inventor networks as studied by patent coinventorships, Research Policy 35, 412-30.

FLEMING L. and FRENKEN K. (2007) The evolution of inventor networks in the Silicon Valley and Boston Regions, Advances in Complex Systems 10, 53-71.

FLeMING L., KING III C. and JUDA A. I. (2007) Small worlds and regional innovation, Organization Science 18, 938-54.

FRIEDKIN N. (1981) The development of structure in random networks: an analysis of the effects of increasing network density on five measures of structure, Social Networks 3, 41-52. 
GIULIANI E. (2007) The structure of knowledge networks. Uneven and selective, not pervasive and collective. , In: Applied Evolutionary Economics and Economic Geography, edited by FRENKEN K., Cheltenham/Northampton: Edward Elgar.

GLÜCKLER J. (2007) Economic Geography and the evolution of networks, Journal of Economic Geography 7, 619-34.

Hall B. H., Jaffe A. B. and Trajtenberg M. (2001). The NBER patent citations data file: lessons, insights and methodological tools: NBER Working Paper 8498.

KLepper S. and Sleeper S. (2005) Entry by spinoffs, Management Science $51,1291-306$.

KRAFFT J. (2004) Entry, exit and knowledge: evidence from a cluster in the info-communications industry, Research Policy 33, 1687-706.

LAZARIC N., LONGHI C. and ThOMAS C. (2008) Gatekeepers of knowledge versus platforms of knowledge: from potential to realized absorptive capacity, Regional Studies 42, 837-52.

LeVinthal D. A. and MARCH J. G. (1993) The myopia of learning, Strategic Management Journal 14, 95-112.

LONGHI C. (1999) Networks, collective learning and technology development in innovative high technology regions: the case of Sophia-Antipolis, Regional Studies 33, 333-42.

(2002) From exogenous to endogenous local development: the cases of the Toulouse and the Sophia-Antipolis technopoles, In: Complexity and industrial clusters: dynamics and models in theory and practice, edited by CURzIO Q. and ForTIS M., Heidelberg: Physica-Verlag. 
LONGHI C. and QUÉRÉ M. (1997) The Sophia-Antipolis project or the uncertain creation of an innovative milieu, In: The dynamics of innovative regions, edited by RATTI R., BRAMANTI A. and GORDON R., Aldershot: Ashgate.

Malmberg A. and MAskell P. (2002) The elusive concept of localization economies: towards a knowledge-based theory of spatial clustering, Environment and Planning A 34, 429-49.

MARKUSEN A. (1996) Sticky places in slippery space: a typology of industrial districts, Economic Geography 72, 293-313.

MARTIN R. and SUNLEY P. (2003) Deconstructing clusters: chaotic concept or policy panacea?, Journal of Economic Geography 3, 5-35.

MAskell P. and Malmberg A. (2007) Myopia, knowledge development and cluster evolution, Journal of Economic Geography 7, 603-18.

Newman M. E. J., Strogatz S. H. and Watts D. J. (2001) Random graphs with arbitrary degree distributions and their applications, Physical Review E 6402, 026118.

Nooteboom B. and Klein-Woolthuis R. (2005) Cluster dynamics, In: Learning from clusters: a critical assessment from an economicgeographical perspective, edited by BoschmA R. A. and KLOOSTERMAN R. C., Dordrecht: Springer Verlag.

QUÉRÉ M. (2002) Territoire et gouvernance locale: le cas de Sophia-Antipolis., Géographie, Economie et Société 4, 335-46.

(2005) Le développement technopolitain en France: quels enseignements pour l'attractivité des territoires?, Revue de l'OFCE 94, 71-96. 
(2007) Sophia-Antipolis as a 'reverse' science park: from exogenous to endogenous development., In: Applied evolutionary economics and economic geography, edited by FRENKEN K., Cheltenham/Northampton: Edward Elgar.

Schmoch U., LaVille F., Patel P. and Frietsch R. (2003). Linking technology areas to industrial sectors: final report to the EC Commission. Karlsruhe/Paris/Brighton: DG Research.

SINGH J. (2005) Collaborative networks as determinants of knowledge diffusion patterns, Management Science 51, 756-70.

SYMISA (2004). Liste des entreprises Sophia-Antipolis 2004-2005.

TeR WAL A. L. J. and BoschmA R. A. (2009a) Applying social network analysis in economic geography: framing some key analytic issues, Annals of Regional Science 43, in press.

(2009b) Co-evolution of Firms, Industries and Networks in Space, Regional Studies, in press, available online as i-First paper, DOI: 10.1080/00343400802662658.

Uzzi B., Amaral L. A. N. and Reed-Tsochas F. (2007) Small-world networks and management science research: a review, European Management Review 4, 77-91.

Uzzı B. and SPIRo J. (2005) Collaboration and creativity: The small world problem, American Journal of Sociology 111, 447-504.

Verspagen B. and DuYsters G. (2004) The small worlds of strategic technology alliances, Technovation $\mathbf{2 4 , 5 6 3 - 7 1 . ~}$

VISSER E. J. (2009) The complementary dynamic effects of clusters and networks, Industry and Innovation 16, 167-95. 
WALKer G., Kogut B. and SHAN W. J. (1997) Social capital, structural holes and the formation of an industry network, Organization Science 8, 10925.

WATERS R. and LAWTON-SMITH H. (2008) Social networks in high-technology local economies: the cases of Oxfordshire and Cambridgeshire, European Urban and Regional Studies 15, 21-37.

WatTS D. J. and Strogatz S. H. (1998) Collective dynamics of 'small-world' networks, Nature 393, 440-42.

ZANDER U. and KOGUT B. (1995) Knowledge and the speed of the transfer and imitation of organizational capabilities: an empirical test, Organization Science 6, 76-92. 
Figure 1: Emergence of the business park of Sophia-Antipolis $\vee$ Source: QUÉRÉ (2005)

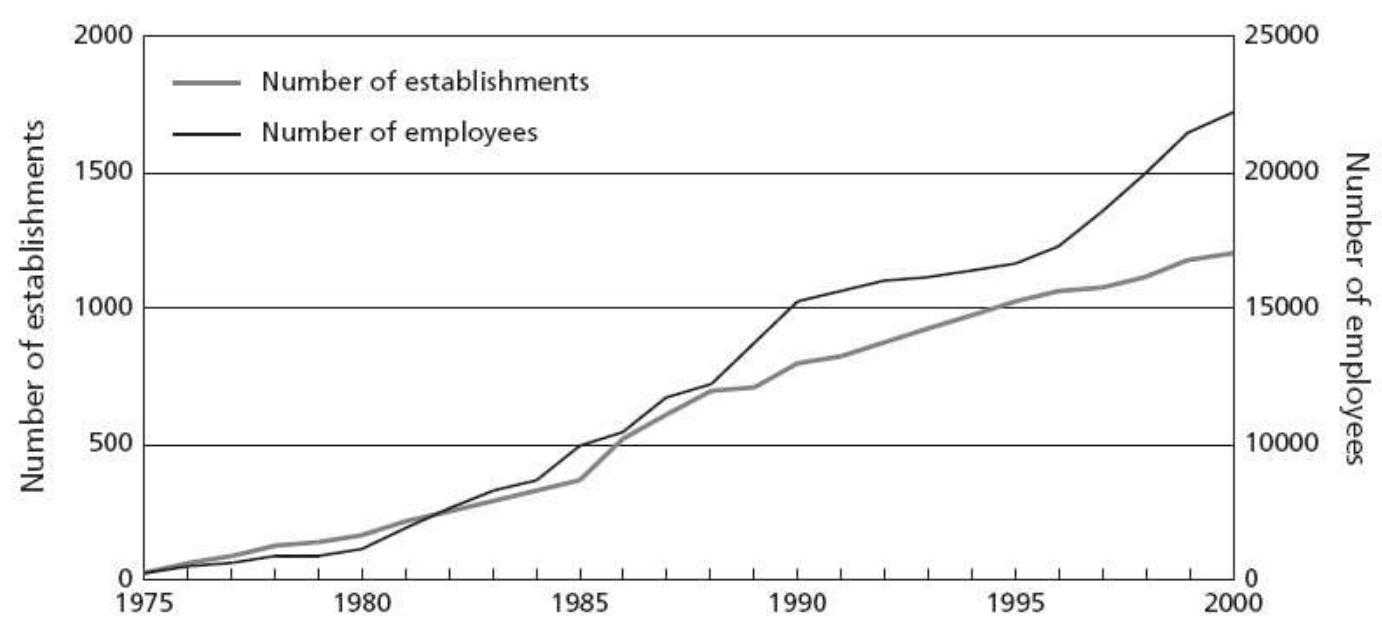


Figure 2: Growth in number of establishments ${ }^{v}$ and employees in Sophia-

\section{Antipolis}

Source: QUÉRÉ (2005)
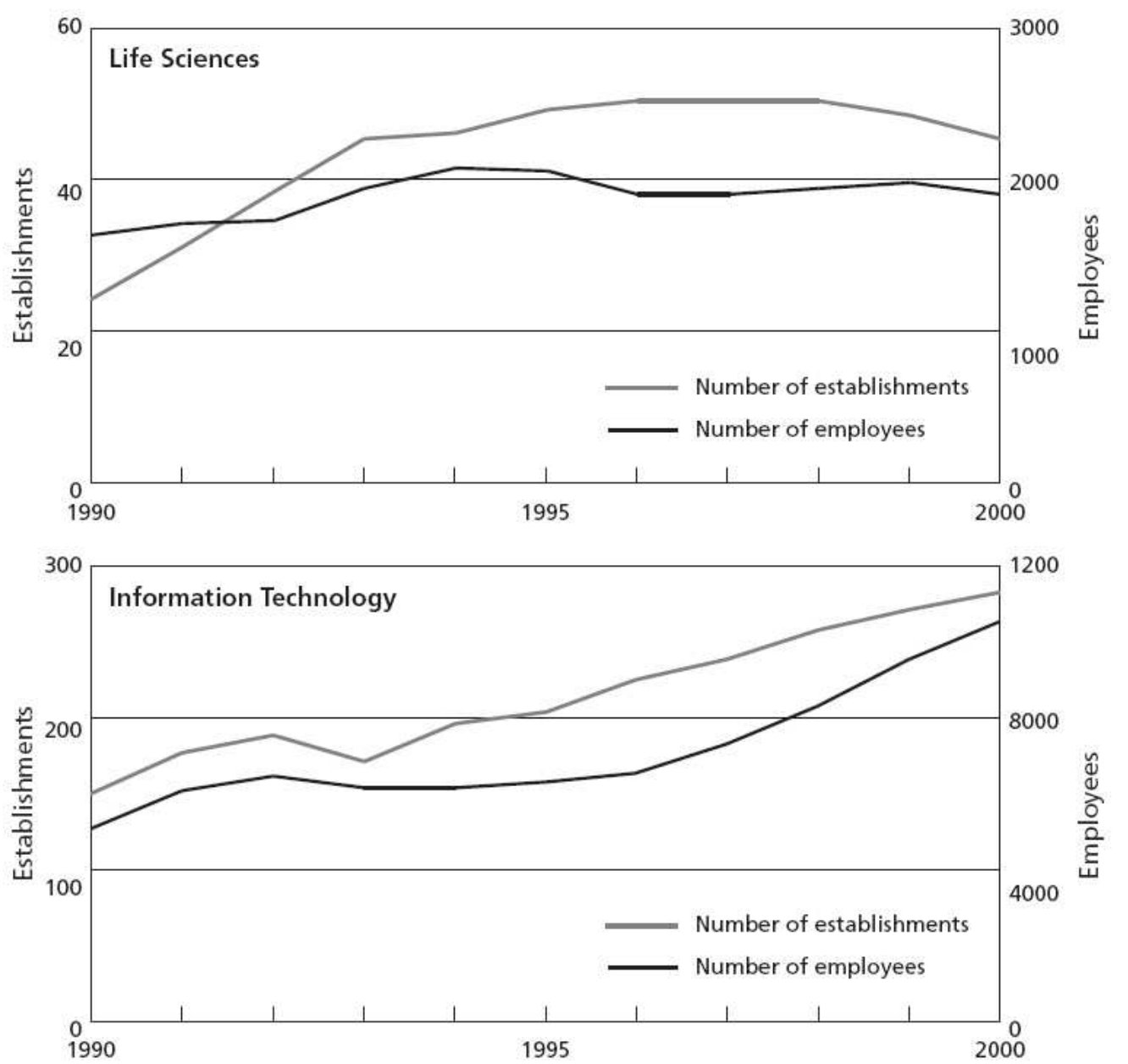
Figure 3: Number of patents and inventors for EPO and USPTO data sources
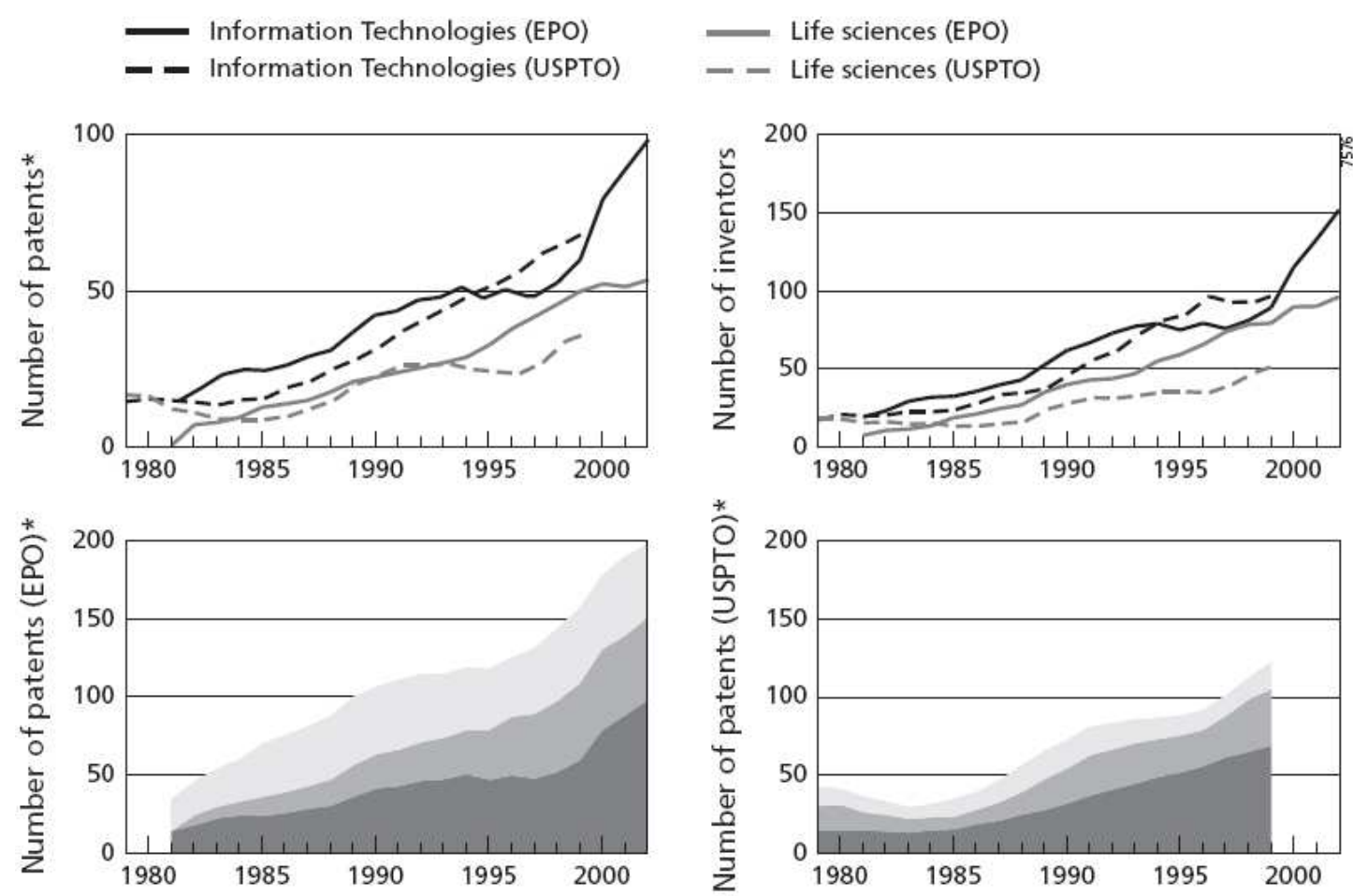
Table 1: EPO and USPTO patent data sources for reconstruction of network evolution

\section{\begin{tabular}{l|l} 
EPO Patents & USPTO Patents
\end{tabular}}

1978-2002

1975-1999

\begin{tabular}{|lcc|}
\hline All sectors & \\
Number of unique patents & 2860 & 1740 \\
Number of unique inventors & 3530 & 1727 \\
\hline Information Technology & 1350 & 869 \\
Number of unique patents & 1816 & 985 \\
Number of unique inventors & & 523 \\
\hline Life Sciences & 701 & 561 \\
Number of unique patents & 1033 & \\
Number of unique inventors & & \\
\hline
\end{tabular}


Figure 4: Evolution of geographical orientation of actors in Sophia-Antipolis in terms of number of links per geographical scale (left: absolute; right: relative)
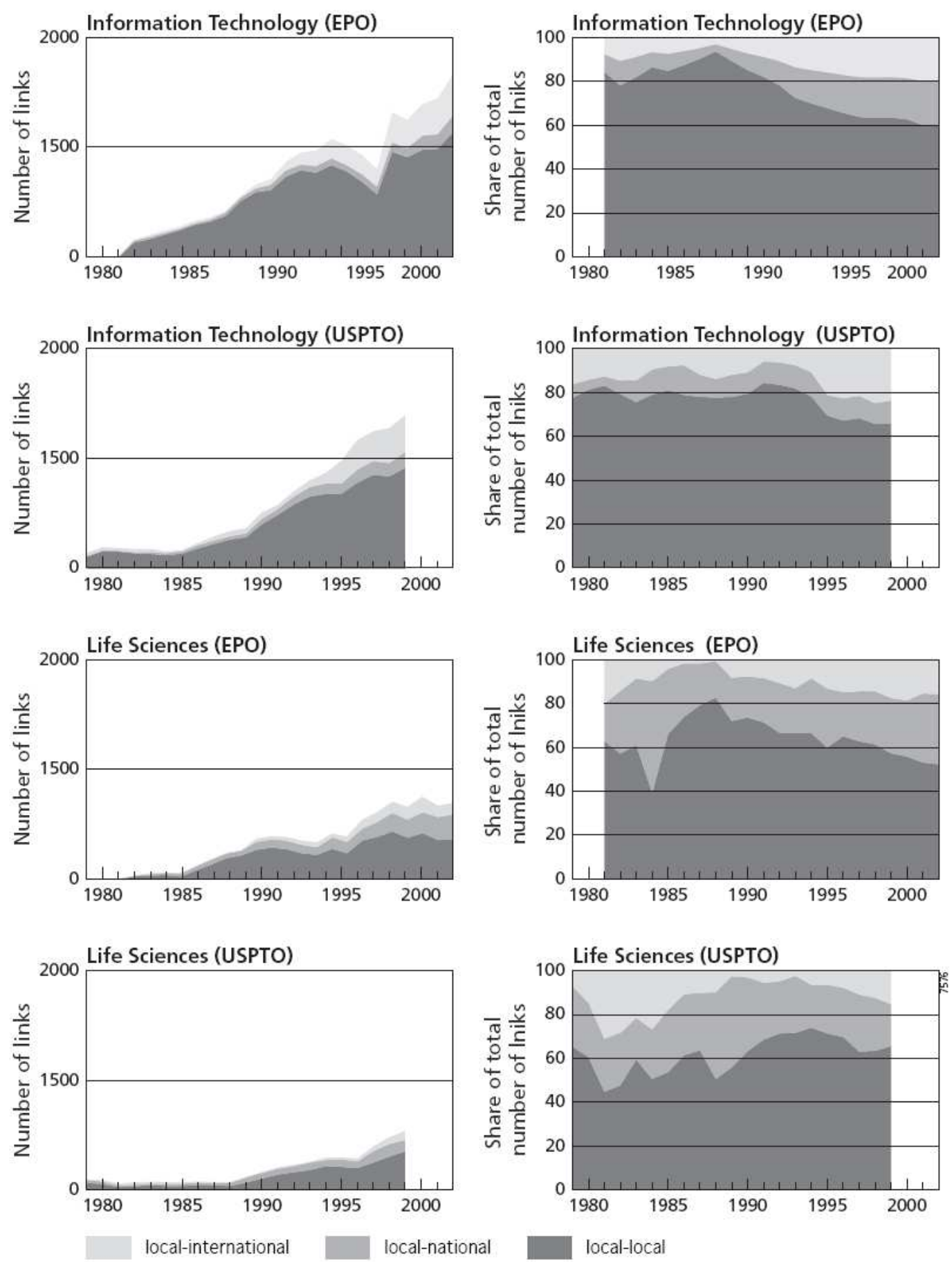
Figure 5: Number of links per inventor

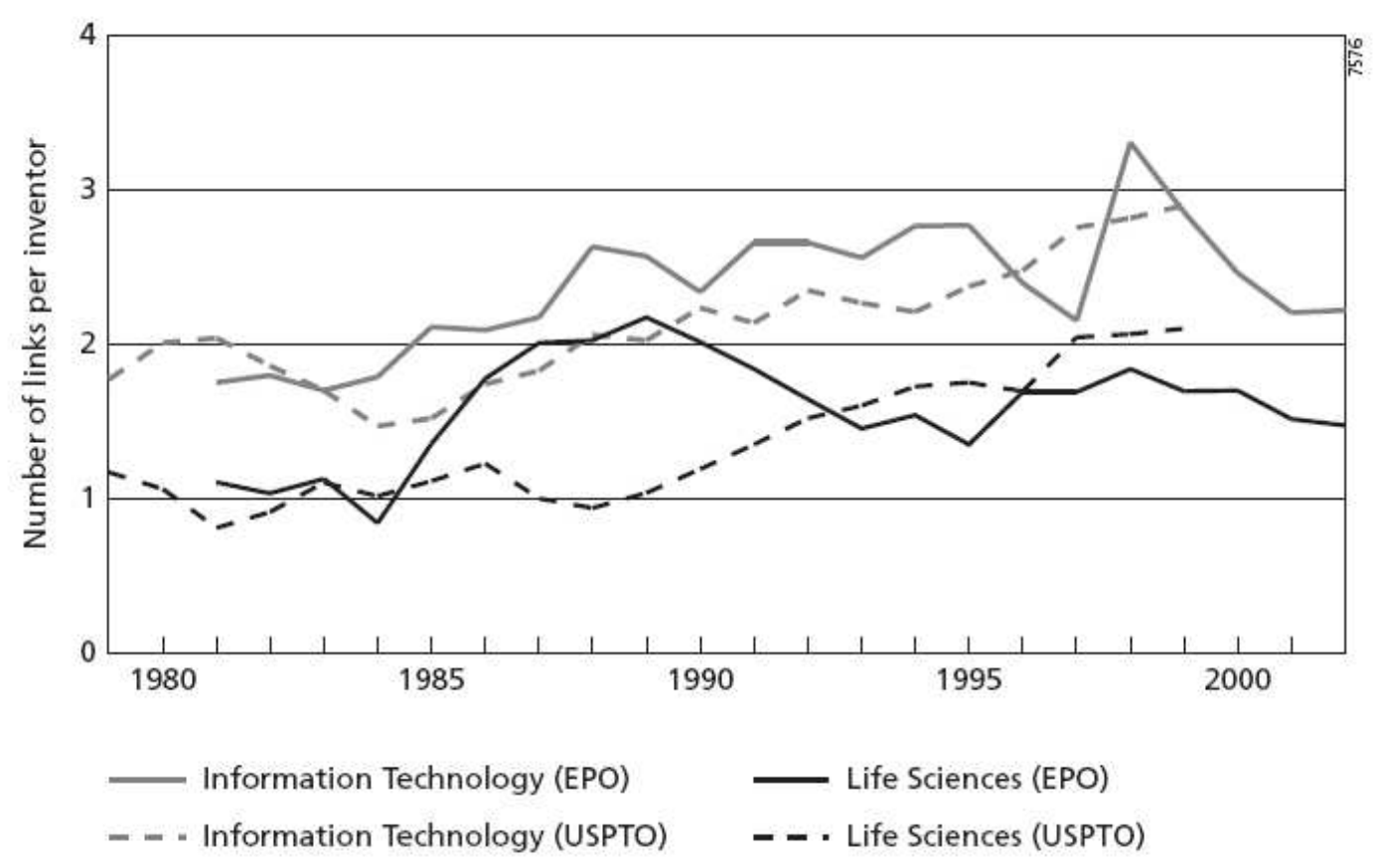

2

3

7

8

10

11

12

13

14

15

16

17

18

19

20

21

22

23

24

25

26

27

28

29

30

31

32

33

34

35

36

37

38

39

40

41

42

43

44

45

46

47

48

49

50

51

52

53

54

55

56

57

58

59

60 
Figure 6: Evolution of connectivity of the Sophia-Antipolis inventors' network
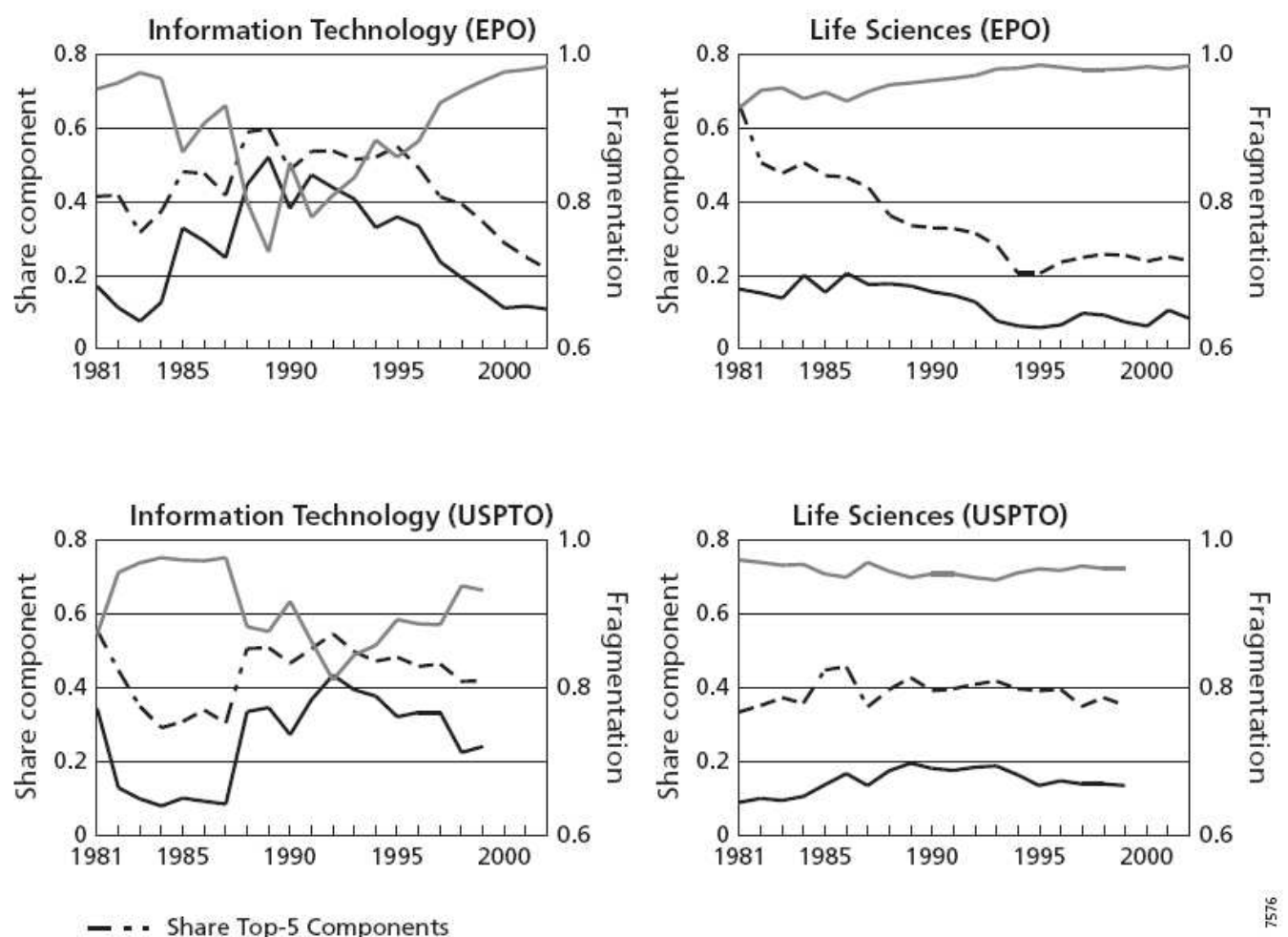

- - Share Top-5 Components 
Figure 7: Evolution of PL- and CC-ratio in Sophia-Antipolis inventors' network
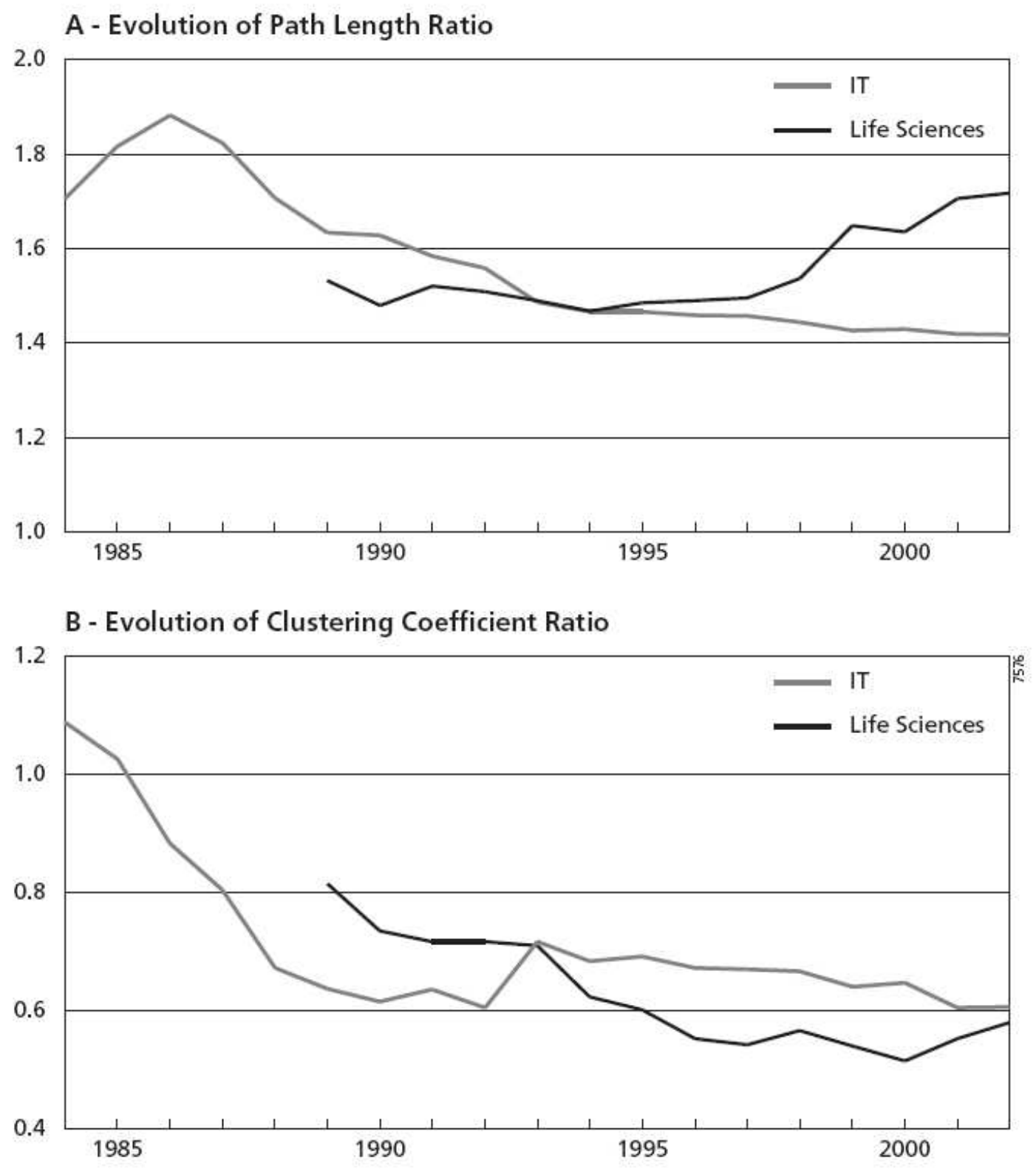

EPO patent data - 5-year moving window procedure - Lines are plotted for the Main Components, starting from MCs of more than 30 nodes 


\section{Appendix 1: allocation of EPO patents to industries}

The Concordance Table as developed by Schmoch et al. (2003) was used in order to allocate EPO patents to Information Technology, Life Sciences or Miscellaneous. The following technological fields have been assigned to Information Technology: 12 Audiovisual Technology, 13 Telecommunications, 14 Information Technology, 15 Semiconductors, 22 Analysis, measurement and control technology.

The following technological fields have been assigned to Life Sciences: 23 Instruments - Medical Technology, 31 Organic fine chemistry, 32 Macromolecular chemistry and polymers, 33 Life Sciences, cosmetics, 34 Biotechnology, 35 Agriculture and food chemistry, 36 Chemical industry, petrol industry and basic materials chemistry.

\section{Appendix 2: allocation of USPTO patents to industries}

The subcategories as defined by Hall et al. (2001) were used in order to allocate USPTO patents to Information Technology, Life Sciences or Miscellaneous. The following sub-categories have been assigned to Information Technology: 2 Computer and Communications (including Communications, Hardware and Software, Computer Peripherals and Information Storage) and 4Electrical and Electronic (including Electrical Devices, Measuring and Testing, Power Systems and Semiconductor Devices). 


\footnotetext{
' Department of Economic Development at the Regional Council (Conseil Général Alpes-Maritimes), Syndicat SAM, Team Côte d'Azur, Fondation Sophia-Antipolis.

ii INRIA (The French National Institute for Research in Computer Science and Control), Eurécom (a private research centre in communication systems), Ecole des Mines de Paris (Paris Institute of Technology), Nice Sophia-Antipolis University, INRA (French National Institute for Agricultural Research) refused cooperation.

iii The Path Length ratio is the average path length in the actual network over the expected path length in a random network of equal size and density. The actual path length is calculated as the average geodesic distance between all dyads in the network. For calculating the random expected path length the bipartite (two-mode) nature of the network needs to be taken into account. Instead of using the average degree and the number of nodes in the network (as one would do in a one-mode network) one utilizes the number of inventors per patent $(\mu)$ and the number of patents per inventor $(v)$ to approximate the random expected path length.

iv Again, the bipartite nature of the inventor network has implications for the way in which the actual and expected values of the clustering coefficient are calculated. Since all inventors that have worked together on a patent form a fully connected clique, the clustering coefficient is by definition much higher than in a one-mode network. Similar to the expected random path length, the random clustering coefficient takes the average number of inventors per patent $(\mu)$ and the average number of patents per inventor $(v)$ into account. It is assumed that both $\mu$ and $v$ follow a Poissondistribution.

${ }^{\vee}$ Establishments include firms (both SMEs and subsidiaries of multinationals), research institutes and universities.
} 